\title{
GRACE gravitational measurements of tsunamis after the 2004, 2010, and 2011 great earthquakes
}

\author{
Khosro Ghobadi-Far ${ }^{1}$ (1) - Shin-Chan Han ${ }^{1} \cdot$ Sébastien Allgeyer ${ }^{2} \cdot$ Paul Tregoning $^{2}$ - Jeanne Sauber ${ }^{3}$. \\ Saniya Behzadpour ${ }^{4} \cdot$ Torsten Mayer-Gürr $^{4} \cdot$ Nico Sneeuw $^{5} \cdot$ Emile Okal $^{6}$
}

Received: 14 August 2019 / Accepted: 1 July 2020 / Published online: 16 July 2020

(C) The Author(s) 2020

\begin{abstract}
The 2004 Sumatra, 2010 Maule, and 2011 Tohoku great earthquakes triggered tsunamis as large as a few decimeters over a few $100 \mathrm{~km}$ in the open ocean. The transient ocean mass redistribution propagating as tsunamis changed the Earth's gravity field enough to perturb the GRACE satellites' orbits at $\sim 500 \mathrm{~km}$ above the surface. The on-board microwave ranging system detected inter-satellite acceleration anomalies of up to $1.0-4.0 \mathrm{~nm} / \mathrm{s}^{2}$. There is good agreement between GRACE measurements and tsunami models for the three events. Complementarily to buoys, ocean bottom pressure sounders, and satellite altimeters, GRACE is sensitive to the long-wavelength spatial scale of tsunamis and provides an independent source of information for assessing alternate early earthquake and tsunami models. Our study demonstrates an innovative way of applying GRACE and GRACE Follow-On data to detect transient geophysical mass changes which cannot be observed by the conventional monthly Level-2 and mascon solutions.
\end{abstract}

Keywords GRACE · GRACE Follow-On · LOS gravity difference $\cdot$ Tsunami $\cdot$ Earthquake · Transient signals

\section{Introduction}

The Gravity Recovery and Climate Experiment (GRACE) mission measured time-variable global gravity fields with a spatial resolution of $300-400 \mathrm{~km}$ nearly every month for

Electronic supplementary material The online version of this article (https://doi.org/10.1007/s00190-020-01395-3) contains supplementary material, which is available to authorized users.

Khosro Ghobadi-Far

khosro.ghobadifar@uon.edu.au

1 School of Engineering, University of Newcastle, Callaghan, Australia

2 Research School of Earth Sciences, Australian National University, Canberra, Australia

3 Geodesy and Geophysics Lab, NASA Goddard Space Flight Center, Greenbelt, MD, USA

4 Institute of Geodesy, Graz University of Technology, Graz, Austria

5 Institute of Geodesy, University of Stuttgart, Stuttgart, Germany

6 Department of Earth and Planetary Sciences, Northwestern University, Evanston, IL, USA
15 years from 2002 to 2017 (Tapley et al. 2004). The conventional data products of the GRACE mission include monthly averaged global snapshots of Earth's gravity field (Level-2 data product, L2) and of surface mass change (Level-3 data products, L3) inferred from the L2 data after removing the elastic Earth loading effect and non-surficial processes such as glacial isostatic adjustment and earthquakes. The monthly surface mass redistribution data have been used to quantify variabilities in terrestrial water storage, ice-sheets and glaciers, and ocean mass (e.g., Tapley et al. 2019). Geophysical processes at such spatial scales are generally characterized by seasonal and inter-annual changes. The monthly solutions seem sufficient to recover the majority of the signals.

However, there are substantial gravitational signals not captured in the conventional monthly L2 data, but that can be obtained from a tailored processing of the GRACE data. For example, the sub-monthly barotropic gyre in the Argentine basin is observed in 10-day gravity solutions (Bruinsma et al. 2010; Han et al. 2014; Yu et al. 2018). Other higherfrequency ocean variability is visible in the residual Level1B (L1B) inter-satellite tracking data (Chambers and Bonin 2012; see also Fig. 1). Various oceanic mass variabilities at different time scales are manifested in inter-satellite ranging data measured by the GRACE K-band ranging (KBR) 


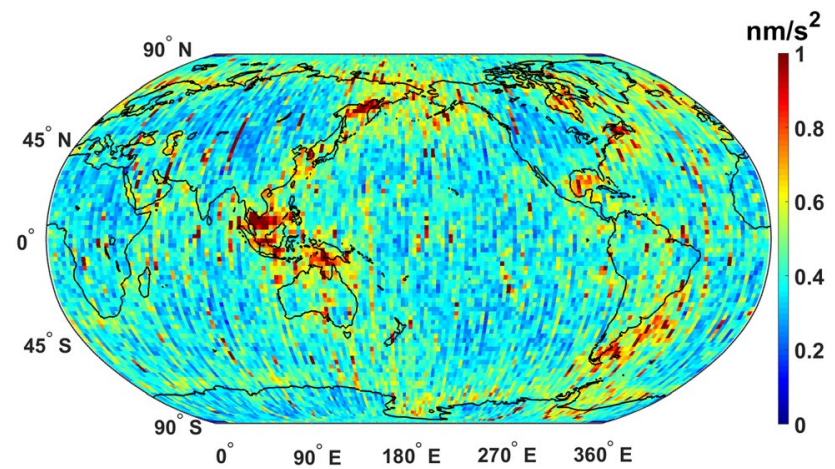

Fig. 1 The RMS variability of the GRACE range-acceleration residuals computed in $2^{\circ} \times 2^{\circ}$ bins based on 3 months of data in December 2004, February 2010, and March 2011. The range-acceleration residuals are low-pass filtered at 50 cycle per revolution to suppress the KBR instrument noise. The median RMS of the residuals is $\sim 0.4 \mathrm{~nm} / \mathrm{s}^{2}$. The largest anomalies are found mostly near the coastal regions. The residuals represent the sub-monthly gravity variation (due to mass redistribution) and are shown to provide context for the larger residuals observed in the open ocean due to tsunamis

system. In this study, we examined unusually intense but short-lasting gravitational variability caused by tsunami waves, discernible at satellite altitudes for less than a day after the earthquakes. Such transient geophysical signals are rarely addressed with GRACE data. Recently, GhobadiFar et al. (2019) studied the Earth's free oscillations excited by the 2004 Sumatra earthquake, which lasted for a few days after the earthquake rupture, using the GRACE KBR residuals.

Transoceanic tsunamis are mainly triggered by sudden displacement of the ocean floor by earthquakes. During the GRACE era from 2002 to 2017, three great earthquakes [2004 Sumatra (Indonesia), 2010 Maule (Chile), and 2011 Tohoku (Japan)] generated large transoceanic tsunamis. In the open ocean, changes in the ocean mass load caused by the tsunami waves were detected by ocean bottom pressure gauges (e.g., Saito et al. 2010; Yoshimoto et al. 2016) and the tsunami sea surface height variations were observed by satellite altimetry (e.g., Smith et al. 2005; Song et al. 2005; Fujii and Satake 2007, 2013; Song et al. 2012; Hamlington et al. 2012). These observations have been used for studying the mechanism of large tsunamis in the open ocean, improving tsunami model simulation and prediction, as well as constraining earthquake sources. However, these measurements are local samples of extensive tsunamis and may not necessarily provide information on the overall sea surface disturbance.

In this study, we introduce a new space-borne technique with a wide field of view for offshore tsunami observation that measures the gravitational effect of tsunami-induced ocean mass change. The gravitational signature of tsunamis is manifested in the inter-satellite ranging between the two GRACE satellites. We demonstrate how inter-satellite distances were perturbed by transient gravity changes from the 2004 Sumatra, 2010 Maule, and 2011 Tohoku tsunamis, and present unequivocal evidence of the tsunami waves detected in the actual GRACE KBR measurements over 1-14 h after the earthquakes.

\section{GRACE data and tsunami models}

\subsection{GRACE inter-satellite ranging measurements}

We first computed dynamic reference orbits of the GRACE satellites based on the data processing strategy and background models used in ITSG-Grace2018 monthly gravity solutions (Mayer-Gürr et al. 2018) for December 2004, February 2010, and March 2011, covering the time periods of the Sumatra, Maule, and Tohoku tsunamis, respectively. The reference orbits were computed on a daily basis using the non-gravitational accelerometer observations and star camera orientation data as well as the ITSG-Grace2018 monthly mean solution along with several other background models such as the high-frequency (non-tidal) atmosphere and ocean mass variability AOD1B RL06 (Dobslaw et al. 2017), and the updated ocean tides model FES2014b (Carrère et al. 2015) using several years of the GRACE data (Mayer-Gürr et al. 2012). Furthermore, to isolate the gravity change associated with the tsunami from the coseismic gravity change, the coseismic earthquake geopotential models (Han et al. 2013) were also included in the background force models used in the orbit integration (see Figure S1 in supporting information).

The reference range-rate data computed from the dynamic orbits were then subtracted from the GRACE range-rate measurements to obtain the range-rate residuals. As the last step, we applied numerical differentiation to compute range-acceleration residuals from range-rate residuals. The choice of using range-acceleration was made simply because accelerations are better collocated with the location of mass redistribution on the Earth's surface, and thus, they are easier to interpret for regional gravity changes. However, the numerical differentiation amplifies random noise at high frequencies, and hence, low-pass filtering is necessary to accentuate the signals from GRACE range-acceleration data. In our convention, a positive (or negative) mass anomaly on the surface is shown as a trough (or crest) in range-acceleration (Ghobadi-Far et al. 2018b).

The range-acceleration residuals over the oceans represent the high-frequency (sub-monthly) ocean variability not modeled in the AOD1B model as well as the KBR and accelerometer measurement noise and background model errors. Note that GRACE monthly mean solutions included in the 
background models removed the majority of slowly varying (e.g., seasonal and inter-annual) oceanic signals. The root mean square (RMS) of the range-acceleration residuals is typically $\sim 0.4 \mathrm{~nm} / \mathrm{s}^{2}$ in the deep ocean and as large as $1.0 \mathrm{~nm} / \mathrm{s}^{2}$ in some coastal regions (see Fig. 1).

\subsection{Tsunami modeling}

We simulated the tsunami wave propagation using the approach of Allgeyer and Cummins (2014) which solves the shallow-water (2D) equations while accounting for the elastic response of the Earth to tsunami mass load as well as seawater density stratification. Implementation of the elastic loading and density stratification considerably improves the predictions of the travel time and waveform of tsunami waves (see also Inazu and Saito 2013; Tsai et al. 2013; Watada 2013). Moreover, the initial sea level condition for tsunami wave propagation was computed from the water column change by both vertical and horizontal seafloor deformation. The importance of the horizontal forcing in tsunami generation is extensively discussed by Song and Han (2011). We computed the seafloor deformation based on the earthquake source models of Ammon et al. (2005) and Hébert et al. (2007) for the 2004 Sumatra, Fujii and Satake (2013) for the 2010 Maule, and Satake et al. (2013) for the 2011 Tohoku events. These source models for the three earthquakes were, respectively, obtained by geodetic and seismological inversions, tsunami waveforms plus coastal geodetic data, and tsunami waveforms. The tsunami models were computed on a $2^{\prime} \times 2^{\prime}$ grid with a temporal resolution of $1 \mathrm{~s}$ for $24 \mathrm{~h}$ of propagation. The output has been downsampled to a $0.5^{\circ} \times 0.5^{\circ}$ grid (average filter) with a temporal resolution of $1 \mathrm{~min}$ for the purpose of this study.

\section{Method}

We developed a method based on forward modeling of the gravitational effect of tsunami waves along the satellite orbit and direct comparison with the GRACE L1B observation of inter-satellite ranging perturbation. We carried out the model-data comparison in terms of line-of-sight gravity difference (LGD). LGD can be directly estimated from range-acceleration residual, however with a limited accuracy (Weigelt 2017; Ghobadi-Far et al. 2018a). Recently, Ghobadi-Far et al. (2018b) developed a transfer function based on correlation-admittance spectral analysis of rangeacceleration and LGD that can be applied to residual rangeacceleration, enabling accurate LGD determination with an error of $0.15 \mathrm{~nm} / \mathrm{s}^{2}$ over the frequency band higher than 5 cycles per revolution $(\mathrm{CPR} ; 1 \mathrm{CPR}=0.18 \mathrm{mHz})$ or $1 \mathrm{mHz}$ (wavelengths of $8000 \mathrm{~km}$ and smaller). The method is most appropriate for regional applications because of limited accuracy at the low frequency band (less than $5 \mathrm{CPR}$ ).

To compute the gravitational effect of the tsunami wave field along the GRACE orbits in terms of LGD, the grids of tsunami sea surface height change (with a temporal resolution of $1 \mathrm{~min}$ ) were converted into spherical harmonic coefficients of gravitational potential to degree 200. Then, the gravity vector was computed for each GRACE satellite along its reference orbit using the tsunami geopotential coefficients. The tsunami-induced LGD changes were simply obtained by projecting the difference of the gravity vectors between the two satellites in the line-of-sight direction (Ghobadi-Far et al. 2018b).

\section{Results}

\subsection{Sumatra tsunami}

We first extracted the GRACE ground tracks in the region from longitudes of $35^{\circ} \mathrm{E}$ to $130^{\circ} \mathrm{E}$ and latitudes of $40^{\circ} \mathrm{S}$ to $26^{\circ} \mathrm{N}$ over the $24 \mathrm{~h}$ after the Sumatra earthquake, which occurred on 26 December 2004 00:58:53 UTC (Figure S2). We then selected those arcs that matched the tsunami wave propagation in time and space (Figure S3). The GRACE satellites first flew over the tsunami $1 \mathrm{~h} 15$ min after the earthquake in an ascending track, when the tsunami wave height was as large as $40 \mathrm{~cm}$ and the induced surface gravity change was $\sim 20 \mu \mathrm{Gal}$ (Figure S4).

We compared the GRACE observed LGD with the tsunami model LGD computed using the earthquake source model from Ammon et al. (2005), for the arc shown in Fig. 2a. Figure $2 b$ shows the model LGD (in blue) and GRACE observation (in red) time series as a function of latitude. We applied low-pass filtering at $50 \mathrm{CPR}$ to suppress the high-frequency noise in the GRACE LGD data. The two negative anomalies of -2.5 and $-2 \mathrm{~nm} / \mathrm{s}^{2}$ found in the GRACE LGD data at latitudes $5^{\circ} \mathrm{S}$ and $15^{\circ} \mathrm{N}$, respectively, correspond to the positive tsunami wave around the same latitudes where the southern and northern leading edges of the tsunami are located. The large crest of $4 \mathrm{~nm} / \mathrm{s}^{2}$ found at latitude $5^{\circ} \mathrm{N}$ is caused by the notable negative sea level anomalies found in the model in that region. The remarkable agreement between the GRACE data and tsunami model from latitude $10^{\circ} \mathrm{S}$ to $20^{\circ} \mathrm{N}$ expresses the exceptionally large tsunami ( $40 \mathrm{~cm}$ over wavelengths of few hundred $\mathrm{km}$ ). The orbits of the GRACE satellites were significantly perturbed by the transient gravity change due to the tsunami so that their inter-satellite distance changes were detectable by the KBR system.

If the GRACE LGD observations along the ascending arc in Fig. 2b were to be associated with transient tsunami waves, they should have not appeared along the descending 

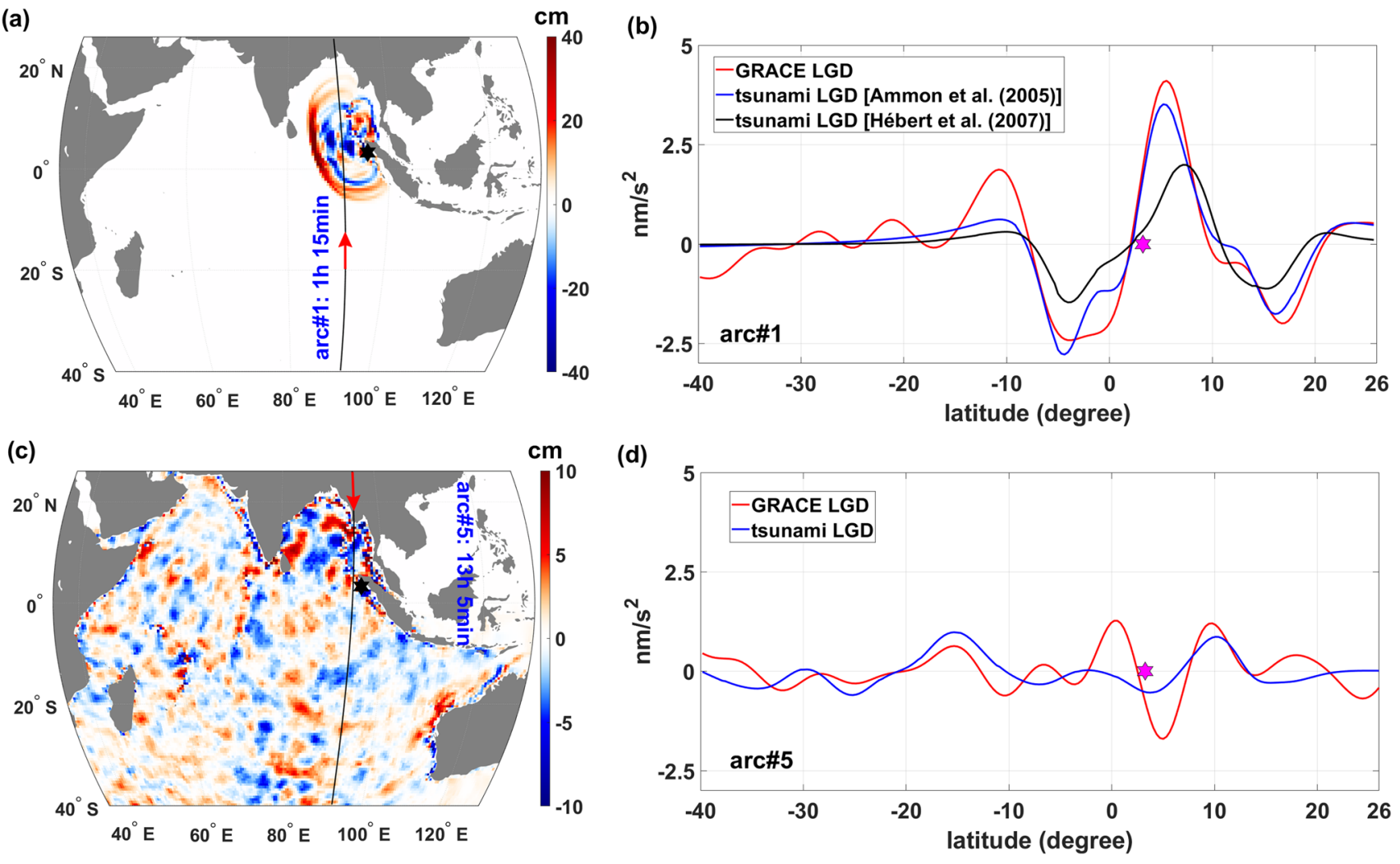

Fig. 2 GRACE observation of the tsunami triggered by the 2004 Sumatra earthquake that occurred on 26 December 2004 00:58:53 UTC. a The GRACE ascending track $1 \mathrm{~h} 15 \mathrm{~min}$ after the rupture along with the tsunami wave field at the same time. b Comparison between the GRACE observed (red), low-pass filtered at $50 \mathrm{CPR}$, and tsunami model LGD time series, computed based on the earthquake source models of Ammon et al. (2005) in blue and Hébert et al. (2007) in black, along the ascending track shown in panel a. c The GRACE descending track covering the same region $\sim 12 \mathrm{~h}$ after the ascending track in a along with the tsunami wave field at the same time. d Comparison between the GRACE observed and tsunami simulated LGD along the descending track shown in $\mathbf{c}$. The

arc crossing the same region with $\sim 12 \mathrm{~h}$ of time difference because tsunamis would not last over the region for such a long period. To demonstrate this, we compared the GRACE LGD data along the ascending track (Fig. 2a) with the descending track (Fig. 2c) covering the same region most closely but roughly $12 \mathrm{~h}$ later. The LGD data from the descending track and the corresponding model synthetics are shown in Fig. 2d. With the diffusive tsunami propagation, we do not expect to observe the same size of gravitational perturbation $12 \mathrm{~h}$ later. As expected, both the GRACE data and the model show no significant anomaly in the descending track (Fig. 2d). For other cases of GRACE overpassing tsunamis (such as arc numbers 5, 6, and 7 in Figure S3), the tsunami signal did not emerge from the GRACE data due to the measurement noise as well as natural oceanic variability. comparison of ascending and descending arcs demonstrates that the ocean mass change detected by GRACE along the ascending arc \#1, which matches the tsunami model, is indeed associated with the transient tsunami waves, because the same GRACE signal does not appear along the descending arc \#5 passing over the same region. The star indicates the epicenter of the earthquake, and LGD denotes line-of-sight gravity difference. For the reference to the GRACE arc numbers, see Figure S2 in supporting information. GRACE satellites completed one orbital revolution around the Earth in $\sim 90 \mathrm{~min}$, so it took them $\sim 15 \mathrm{~min}$ to cross the Indian Ocean from latitude $40^{\circ} \mathrm{S}$ to $20^{\circ} \mathrm{N}$

To quantify the agreement between GRACE and the tsunami model, we applied consistent low-pass filters to both the GRACE and tsunami LGD time series at 40, 50, and 60 CPR frequencies (see Figure S5). The correlation coefficients between GRACE and the tsunami model from latitude $10^{\circ} \mathrm{S}$ to $20^{\circ} \mathrm{N}$, where GRACE satellites were over the tsunami waves, are $0.99,0.98$, and 0.98 . The RMS signal reduction, which is computed as $\left(1-\frac{\operatorname{RMS}\left(\mathrm{LGD}^{\mathrm{GRACE}}-\mathrm{LGD}^{\mathrm{s} \text { sunami }}\right)}{\left.\mathrm{RMS}^{\mathrm{LGGD}}{ }^{\mathrm{GRACE}}\right)}\right)$, is $0.79,0.76$, and 0.74 , respectively. We note that the same results in terms of correlation and RMS reduction were obtained when we applied a band-pass filter between 5 and 50 CPR to GRACE and tsunami data along the arc number 1. To demonstrate the statistical significance of the results, we also compared the GRACE LGD along the arc number 5 sampling the same region with $\sim 12 \mathrm{~h}$ of difference (Fig. 2c) with the tsunami LGD along arc number 1 . The 
correlation and RMS reduction in this case is reduced to -0.50 and -1.84 , respectively (see Table $S 1$ in supporting information). This is due to the dissipation of tsunami waves over time.

We examined the GRACE tsunami data for contrasting different earthquake source models, as done in Han et al. (2010) but using the solid Earth deformation signals (not tsunamis). We computed the model LGD perturbation with the seismic source of Hébert et al. (2007), shown in black in Fig. 2b. It is seen that the tsunami model with the seismic source from Ammon et al. (2005), which is closer to the moment release estimate by Okal and Stein (2009) using ultra-long period normal mode data, compares better with the GRACE data in terms of both amplitude and phase. This example shows a potential benefit of GRACE-like data for assessing alternate early source models, improving tsunami model simulations, and providing enhanced constraints on seismic source parameters.

\subsection{Maule tsunami}

We found a total of 14 GRACE ground tracks in the region from longitudes of $130^{\circ} \mathrm{E}$ to $300^{\circ} \mathrm{E}$ and latitudes of $70^{\circ} \mathrm{S}$ to $70^{\circ} \mathrm{N}$ in the $24 \mathrm{~h}$ after the 2010 Maule earthquake, which occurred on 27 February 2010 06:34:11 UTC (Figure S6). Unfortunately, the first two tracks that match the tsunami propagation in time and space do not occur until 11, and $12 \mathrm{~h}$ 30 min after the earthquake (arc numbers 7 and 8 in Figure S7). By that time, the tsunami wave energy had dissipated, with the largest remaining amplitude being $<10 \mathrm{~cm}$ at the wave front.

We examined in detail arc number 9, where the GRACE satellites passed over the center of the leading edge of the tsunami waves in an ascending track $\sim 14 \mathrm{~h}$ after the earthquake. Figure $3 \mathrm{a}$ shows that the leading edge at latitude of $\sim 30^{\circ}$ E propagates northwest with an amplitude of $\sim 10 \mathrm{~cm}$ and an equivalent surface gravity change of $\sim 4$ $\mu \mathrm{Gal}$ (Figure S8). The observed and simulated LGD agrees over latitudes $20^{\circ} \mathrm{N}$ to $40^{\circ} \mathrm{N}$ (Fig. 3b). GRACE detected

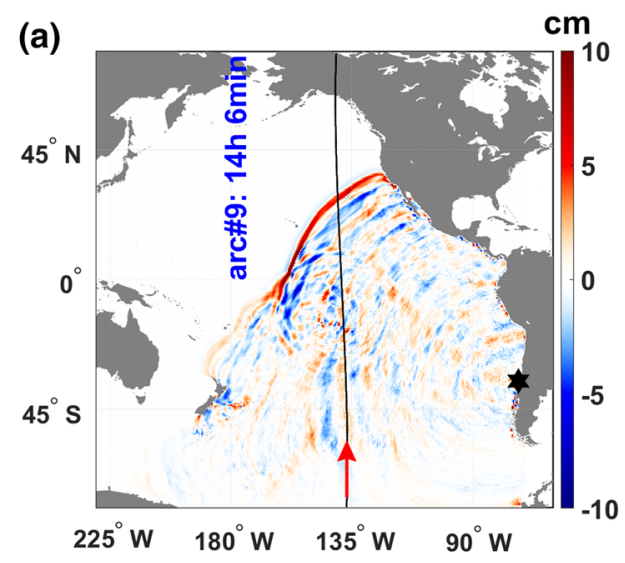

(b)
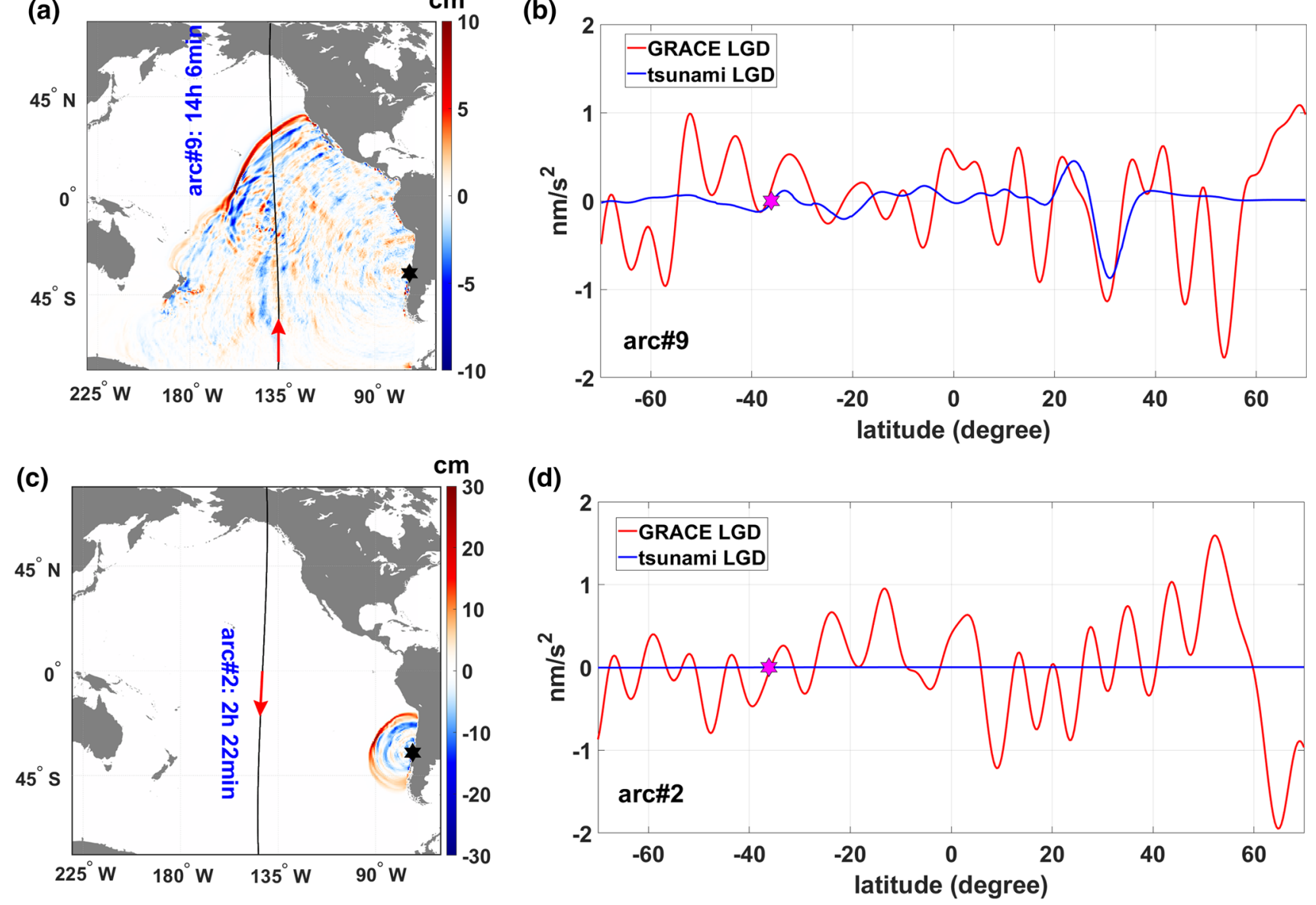

Fig. 3 GRACE observation of the tsunami triggered by the 2010 Maule earthquake occurred on 27 February 2010 06:34:11 UTC. See the caption of Fig. 2 for details about each panel. GRACE detected

the large sea level changes near the leading edge of the tsunami at latitude $30^{\circ}$ N. See Figure S10 in supporting information for another similar case 
the positive sea level change at the leading edge of the tsunami as well as other oceanic variability in other regions with similar sea level perturbation. Such a signal is not found in the GRACE LGD from latitude $20^{\circ} \mathrm{N}$ to $40^{\circ} \mathrm{N}$ along the descending track crossing the same region $\sim 12 \mathrm{~h}$ before (Fig. 3c, d). The correlation and RMS reduction between the low-pass filtered GRACE and tsunami model LGD at 40 CPR along the ascending arc number 9 from latitude $20^{\circ} \mathrm{N}$ to $40^{\circ} \mathrm{N}$ are $\sim 0.9$ and 0.60 , respectively, and slightly less agreement is found when higher CPR is used (see Figure S9). To show the statistical significance of these values, we note that the correlation and RMS reduction between GRACE LGD along the descending arc number 2 (Fig. 3c), which passes over the same region as the arc number 9, and the transient tsunami LGD along the arc number 9 are -0.30 and -0.53 , respectively (see Table S1).

There is another arc of the GRACE satellites crossing over the tsunami (arc number 10 in Figure S7), an ascending arc 90 min after arc number 9 shown in Fig. 3. The results of GRACE and model comparison for this pass are shown in Figure S10. The largest signals are observed near the equator, where the GRACE satellites detected the wave front.

\subsection{Tohoku tsunami}

The 2011 Tohoku earthquake triggered a catastrophic tsunami on 11 March 2011 at 05:46:24 UTC. The GRACE satellites first flew over the tsunami on a descending track about $3 \mathrm{~h} 45$ min after the earthquake (Figure S11 and S12). Figure $4 \mathrm{a}$ shows that the GRACE satellites flew over the tsunami wave field into the northward propagating wave front at latitude of $55^{\circ} \mathrm{N}$, and exited from the southward propagating wave front at latitude $10^{\circ} \mathrm{N}$. The southward leading edge is particularly prominent with an amplitude of $20 \mathrm{~cm}$ and surface gravity change of $8 \mu \mathrm{Gal}$ (Figure S13). The GRACE LGD observations agree well with the tsunami model over
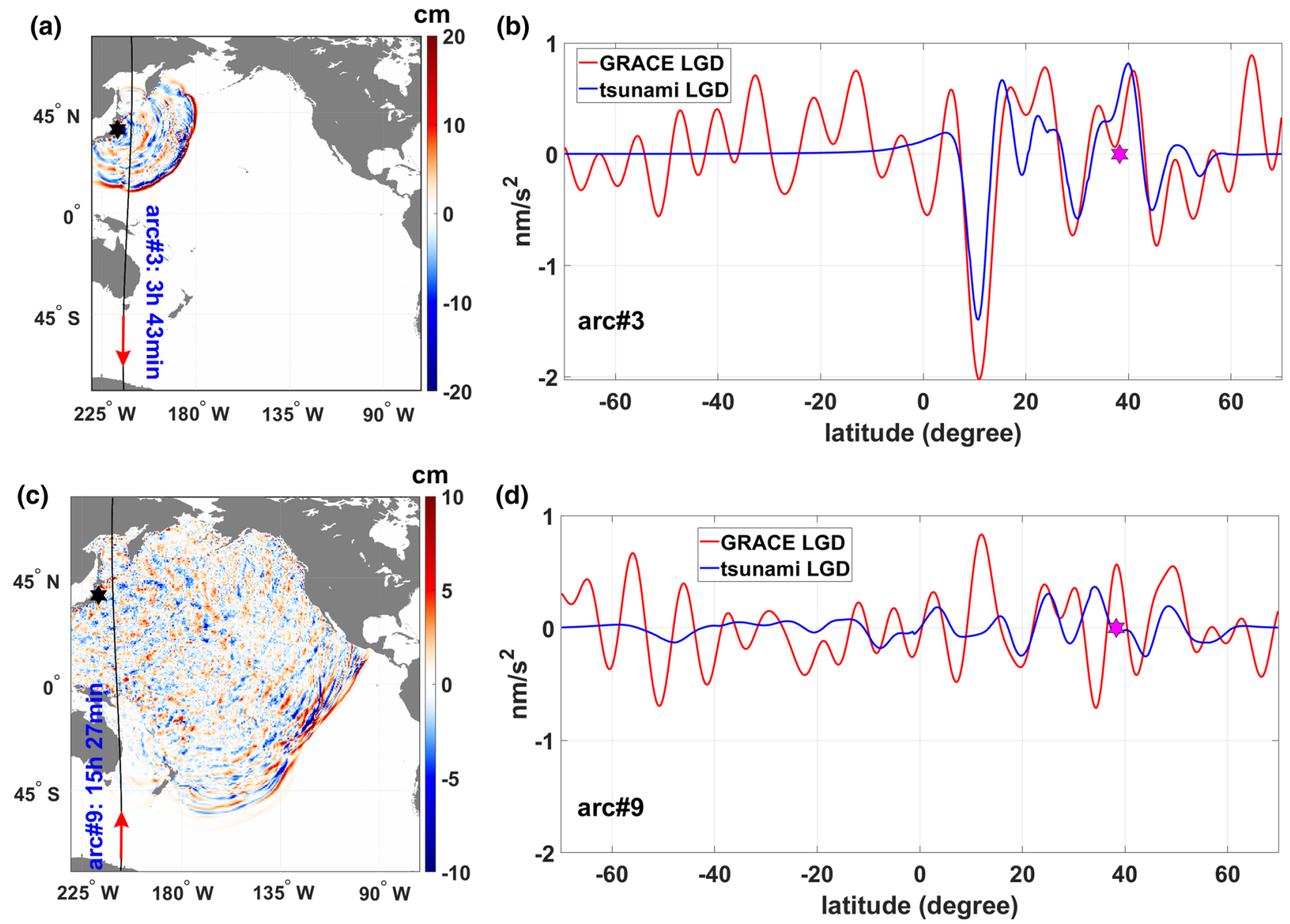

Fig. 4 GRACE observation of the tsunami triggered by the 2011 Tohoku earthquake occurred on 11 March 2011 05:46:24 UTC. See the caption of Fig. 2 for details about each panel. See Figures S15 and S16 in supporting information for other possible cases of tsunami detection by GRACE 
latitudes of $5^{\circ} \mathrm{N}$ to $60^{\circ} \mathrm{N}$ where the model predicts a large LGD perturbation (Fig. 4b). The sharp and intense peak of the LGD anomaly of up to $-2 \mathrm{~nm} / \mathrm{s}^{2}$ at $10^{\circ} \mathrm{N}$ is a clear indication of the southern wave front.

The GRACE arc number 9 sampled the same area in an ascending track $12 \mathrm{~h}$ after arc number 3 (Fig. 4c). By that time, the tsunami wave field had diminished in that area to less than $\pm 5 \mathrm{~cm}$, resulting in a less distinguishable tsunami LGD anomaly relative to inherent ocean variability (Fig. 4d). Low-pass filtering of the observed and simulated LGD at the same cutoff frequencies along the descending arc number 3 from latitude $0^{\circ} \mathrm{N}$ to $60^{\circ} \mathrm{N}$ results in correlation $\geq 0.8$ and RMS reduction $\geq 0.40$ (see Figure S14). These high correlation and RMS reduction values are reduced to -0.16 and -0.67 , respectively, when GRACE LGD along the ascending arc number 9 (Fig. 4c), which covers the same region as arc number 3, is compared to transient tsunami LGD along the arc number 3 , illustrating that the gravitational anomalies from latitude $0^{\circ} \mathrm{N}$ to $60^{\circ} \mathrm{N}$ were indeed transient (less than $\sim 12 \mathrm{~h}$ ) as expected from tsunami-induced ocean mass changes (see Table S1). The additional comparison for two other possible arcs (number 7 and 8 ) is also shown in Figures S15 and S16, where the signals from the GRACE data and the model are smaller but still positively correlated.

\section{Summary and prospect}

We presented a novel approach of analyzing GRACE intersatellite ranging measurements to model transient gravitational changes associated with the 2004 Sumatra, 2010 Maule, and 2011 Tohoku tsunamis. The method is based on the residual KBR data with respect to the monthly mean gravity field. The transient signals are not modeled in the monthly mean L2 gravity fields but remain in the residual L1B data. We exploited the linear relationship in the spectral domain between inter-satellite range-acceleration (second time-derivative of range) and line-of-sight gravity difference between the two GRACE satellites to evaluate the gravitational perturbation by tsunamis along the satellite orbits.

All three tsunamis were as large as a few decimeters over wavelengths of hundreds of $\mathrm{km}$ in the open ocean. Expectedly, the largest anomalies of sea surface height changes were observed at the wave front. Despite the polar orbit of GRACE satellites, there were still a few instances when the satellites were flying over the tsunami waves before they dissipated after $10-15 \mathrm{~h}$. The KBR residuals in the open ocean are generally on the order of $0.4 \mathrm{~nm} / \mathrm{s}^{2}$ in terms of RMS variability, roughly translated into several $\mathrm{cm}$ of ocean mass variability. The tsunami gravitational changes measured by GRACE were up to $4.0,1.0$, and $1.5 \mathrm{~nm} / \mathrm{s}^{2}$, respectively, for the 2004, 2010, and 2011 tsunamis. There are high correlations between GRACE measurements and tsunami models (up to 0.98) for all events and all cases of GRACE overpasses over the tsunami wave field, when greater than $\sim 10 \mathrm{~cm}$ in amplitude.

It should be mentioned that the discrepancy between GRACE observations and tsunami models is mainly due to modeling uncertainty (tsunami and earthquake) as well as mis- and un-modeled high-frequency atmosphere and ocean signals in the GRACE KBR residuals. Comparison of GRACE observations along the ascending and descending arcs covering the same region (but $\sim 12 \mathrm{~h}$ apart) showed the high-frequency nature of such observations and provided further evidence for tsunami detection. We provided further analysis to demonstrate the statistical significance of our results by comparing tsunami signals with all GRACE data along the arcs covering the same region in December 2004, February 2010, and March 2011 (see Table S2).

Whereas GPS can measure coseismic land deformation, and DART sensors or satellite altimeters observe tsunami sea surface height changes, GRACE data are sensitive to gravitational changes caused by both tsunami and land deformation. In contrast to point-wise ocean bottom pressure measurements and cross-sectional satellite altimeter profiling of tsunami heights, the GRACE gravimetric observations provide regional averages of tsunami-induced gravity changes in the open ocean. The GRACE data essentially represent the long-wavelength components of tsunami (typically $\geq 2000 \mathrm{~km}$; see Fig. 5); in the shallowwater approximation, this corresponds to frequencies of $10^{-4} \mathrm{~Hz}$ and under, which transcend the domain accessible by seismological studies, intrinsically limited to the gravest mode of the Earth $(0.31 \mathrm{mHz})$. This is a result of the layer of space between the Earth's surface and the satellites' orbit acting as a powerful low-pass spatial filter for perturbations of the gravitational potential, which must satisfy Laplace's equation in a medium with zero density, and thus decay rapidly with height for smaller lateral wavelengths. In this context, the GRACE methodology introduced here has the potential to explore the properties of tsunamis (and hence of their parent earthquakes) in a hitherto unexplored domain of frequencies. Being unusually sensitive to the regional scale of tsunamis, the GRACE data can be used for assessing early models of earthquakes and tsunamis after the events to provide independent estimates of the overall tsunami size which are possibly less biased than those derived from sparsely located in situ buoy records.

Our study demonstrated a new application of GRACE microwave inter-satellite tracking data to study gravitational changes from transient (high-frequency) geophysical processes with tsunamis as an example. Equipped with an improved KBR system and laser ranging interferometer (Landerer et al. 2020), the GRACE Follow-on satellites will 


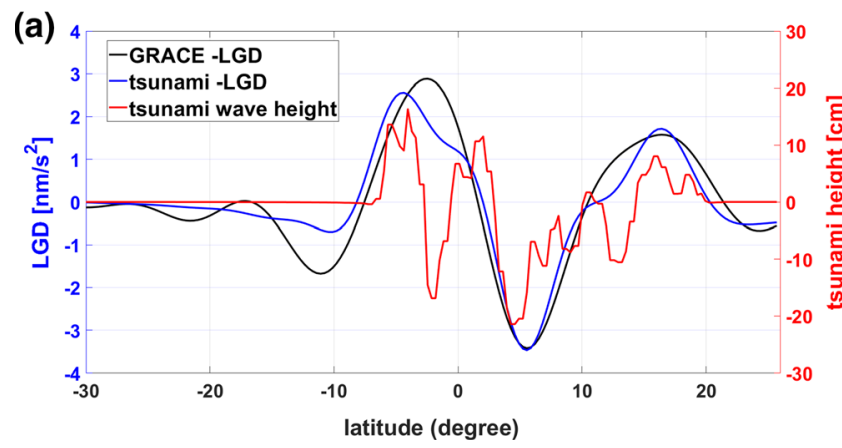

Fig. 5 Simulated tsunami LGD at GRACE orbit (blue) as well as actual GRACE LGD (black), both low-pass filtered at 40 CPR, in comparison to the simulated tsunami sea level change evaluated along the ground track of GRACE satellites (red) for the case of a the 2004 Sumatra tsunami and b the 2011 Tohoku tsunami. The left and right vertical axes indicate LGD in $\mathrm{nm} / \mathrm{s}^{2}$ and tsunami height in

reduce the detection threshold for measuring gravity changes and may lead to more accurate detection of tsunamis as they propagate across major ocean basins, as well as other transient geophysical mass changes. The L1B processing strategy can be optimized so as to deliver low-latency GRACE Follow-on measurements.

Acknowledgements This work was funded by The University of Newcastle to support NASA's GRACE and GRACE Follow-On projects as an international science team member to the missions and by an Australian Research Council Discovery Grant (DP170100224). Science team funding was provided by NASA (GRACERFO19-0010) to Jeanne Sauber. Tsunami simulations were undertaken with the assistance of the resources and services from the National Computational Infrastructure (NCI), Project tz21, which is supported by the Australian Government.

Authors' contribution KG-F, S-CH, and JS designed the research; SA and EO performed the tsunami modeling; SB computed the KBR residuals; KG-F conducted the numerical analysis and drafted the manuscript; and all authors discussed the results and commented on the manuscript.

Data availability The GRACE Level-1B data used in this study were obtained from https://podaac.jpl.nasa.gov/GRACE, and the background models used to compute KBR residuals are available at ftp:// tugraz.at/outgoing/ITSG/GRACE/ITSG-Grace2018/monthly/month ly_background. For tsunami modeling, the earthquake source models were taken from Ammon et al. (2005), Hébert et al. (2007), Fujii and Satake (2013), and Satake et al. (2013), and bathymetry from the 30" GEBCO grid (IOC et al. 2003; available at https://www.gebco.net/ data_and_products/gridded_bathymetry_data/).

Open Access This article is licensed under a Creative Commons Attribution 4.0 International License, which permits use, sharing, adaptation, distribution and reproduction in any medium or format, as long as you give appropriate credit to the original author(s) and the source, provide a link to the Creative Commons licence, and indicate if changes were made. The images or other third party material in this article are included in the article's Creative Commons licence, unless indicated otherwise in a credit line to the material. If material is not included in

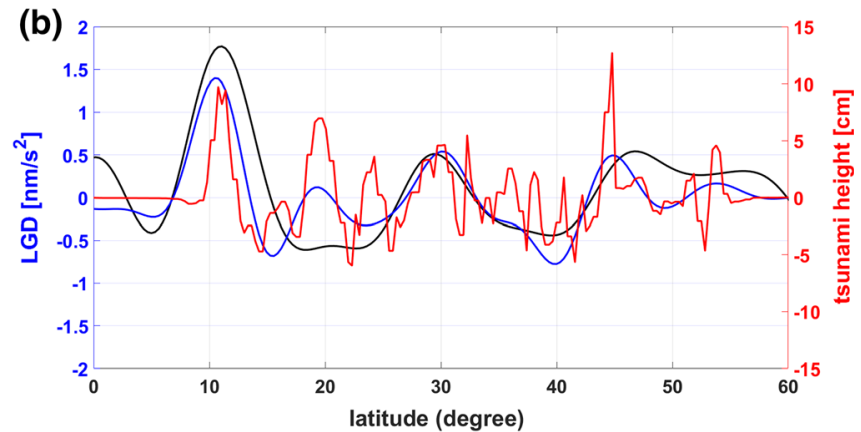

$\mathrm{cm}$, respectively. Note that the sign of LGD is reversed for better visual comparison. This figure illustrates that the GRACE gravimetric observable, as opposed to satellite altimetry measurements, is especially sensitive to the long-wavelength components of the tsunami wave field

the article's Creative Commons licence and your intended use is not permitted by statutory regulation or exceeds the permitted use, you will need to obtain permission directly from the copyright holder. To view a copy of this licence, visit http://creativecommons.org/licenses/by/4.0/.

\section{References}

Allgeyer S, Cummins P (2014) Numerical tsunami simulation including elastic loading and seawater density stratification. Geophys Res Lett 41(7):2368-2375. https://doi.org/10.1002/2014GL0593 48

Ammon CJ, Ji C, Thio HK, Robinson D, Ni S, Hjorleifsdottir V et al (2005) Rupture process of the 2004 Sumatra-Andaman earthquake. Science 308(5725):1133-1139. https://doi.org/10.1126/ science. 1112260

Carrère L, Lyard F, Cancet M, Guillot A (2015) FES 2014, a new tidal model on the global ocean with enhanced accuracy in shallow seas and in the Arctic region. Paper presented at The EGU General Assembly, Vienna

Chambers DP, Bonin JA (2012) Evaluation of Release-05 GRACE time-variable gravity coefficients over the ocean. Ocean Sci 8(5):859-868

Dobslaw H, Bergmann-Wolf I, Dill R, Poropat L, Thomas M, Dahle $C$ et al (2017) A new high-resolution model of non-tidal atmosphere and ocean mass variability for de-aliasing of satellite gravity observations: AOD1B RL06. Geophys J Int 211(1):263-269. https ://doi.org/10.1093/gji/ggx302

Fujii Y, Satake K (2007) Tsunami source of the 2004 SumatraAndaman earthquake inferred from tide gauge and satellite data. Bull Seismol Soc Am 97(1A):S192-S207. https://doi. org/10.1785/0120050613

Fujii Y, Satake K (2013) Slip distribution and seismic moment of the 2010 and 1960 Chilean earthquakes inferred from tsunami waveforms and coastal geodetic data. Pure Appl Geophys 170(910):1493-1509. https://doi.org/10.1007/s00024-012-0524-2

Ghobadi-Far K, Han SC, Loomis BD, Luthcke SB (2018a) On computation of potential, gravity and gravity gradient from GRACE inter-satellite ranging data: a systematic study. In: International Association of Geodesy Symposia. Springer, Berlin. https://doi. org/10.1007/1345_2018_39 
Ghobadi-Far K, Han SC, Weller S, Loomis BD, Luthcke SB, MayerGürr T, Behzadpour S (2018b) A transfer function between lineof-sight gravity difference and GRACE intersatellite ranging data and an application to hydrological surface mass variation. J Geophys Res Solid Earth 123(10):9186-9201

Ghobadi-Far K, Han SC, Sauber J, Lemoine F, Behzadpour S, MayerGürr T, Sneeuw N, Okal E (2019) Gravitational changes of the Earth's free oscillation from earthquakes: theory and feasibility study using GRACE inter-satellite tracking. J Geophys Res Solid Earth. https://doi.org/10.1029/2019JB017530

Hamlington BD, Leben RR, Godin OA, Gica E, Titov VV, Haines BJ, Desai SD (2012) Could satellite altimetry have improved early detection and warning of the 2011 Tohoku tsunami? Geophys Res Lett. https://doi.org/10.1029/2012GL052386

Han SC, Sauber J, Luthcke S (2010) Regional gravity decrease after the 2010 Maule (Chile) earthquake indicates large-scale mass redistribution. Geophys Res Lett. https://doi.org/10.1029/2010GL045449

Han SC, Riva R, Sauber J, Okal E (2013) Source parameter inversion for recent great earthquakes from a decade-long observation of global gravity fields. J Geophys Res Solid Earth 118(3):12401267. https://doi.org/10.1002/jgrb.50116

Han S-C, Ray R, Hughes C (2014) High-frequency (20-60 days) ocean mass variation over the Argentine basin observed from GRACE, a paper presented at the GRACE Science Team Meeting, Potsdam, Germany, September 29-October 01, 2014; https://www.gfz-potsd am.de/en/section/global-geomonitoring-and-gravity-field/proje cts/gravity-recovery-and-climate-experiment-follow-on-grace -fo-mission/gstm/gstm-2014/

Hébert H, Sladen A, Schindelé F (2007) Numerical modeling of the great 2004 Indian Ocean tsunami: focus on the Mascarene Islands. Bull Seismol Soc Am 97(1A):S208-S222. https://doi. org/10.1785/0120050611

Inazu D, Saito T (2013) Simulation of distant tsunami propagation with a radial loading deformation effect. Earth Planets Space 65(8):835-842. https://doi.org/10.5047/eps.2013.03.010

IOC, Iho, and BODC (2003) Centenary edition of the GEBCO digital atlas, published on CD-ROM on behalf of the Intergovernmental Oceanographic Commission and the International Hydrographic Organization as part of the General Bathymetric Chart of the Oceans. British Oceanographic Data Centre, Liverpool

Landerer FW, Flechtner FM, Save H, Webb FH, Bandikova T, Bertiger WI et al (2020) Extending the global mass change data record: GRACE follow-on instrument and science data performance. Geophys Res Lett. https://doi.org/10.1029/2020GL088306

Mayer-Gürr T, Savcenko R, Bosch W, Daras I, Flechtner F, Dahle C (2012) Ocean tides from satellite altimetry and GRACE. J Geodyn 59:28-38. https://doi.org/10.1016/j.jog.2011.10.009

Mayer-Gürr T, Behzadpur S, Ellmer M, Kvas A, Klinger B, Strasser S, Zehentner N (2018) ITSG-Grace2018-monthly, daily and static gravity field solutions from GRACE. GFZ Data Services. http:// doi.org/10.5880/ICGEM.2018.003

Okal EA, Stein S (2009) Observations of ultra-long period normal modes from the 2004 Sumatra-Andaman earthquake. Phys
Earth Planet Inter 175(1-2):53-62. https://doi.org/10.1016/j. pepi.2009.03.002

Saito T, Matsuzawa T, Obara K, Baba T (2010) Dispersive tsunami of the 2010 Chile earthquake recorded by the high-sampling-rate ocean-bottom pressure gauges. Geophys Res Lett. https://doi. org/10.1029/2010GL045290

Satake K, Fujii Y, Harada T, Namegaya Y (2013) Time and space distribution of coseismic slip of the 2011 Tohoku earthquake as inferred from tsunami waveform data. Bull Seismol Soc Am 103(2B):1473-1492. https://doi.org/10.1785/0120120122

Smith WH, Scharroo R, Titov VV, Arcas D, Arbic BK (2005) Satellite altimeters measure tsunami. Oceanography 18(2):11-13

Song YT, Han SC (2011) Satellite observations defying the long-held tsunami genesis theory. In: Tang DL (ed) Remote sensing of the changing oceans. Springer, Berlin, pp 327-342. https://doi. org/10.1007/978-3-642-16541-2_17

Song YT, Ji C, Fu LL, Zlotnicki V, Shum CK, Yi Y, Hjorleifsdottir V (2005) The 26 December 2004 tsunami source estimated from satellite radar altimetry and seismic waves. Geophys Res Lett. https://doi.org/10.1029/2005GL023683

Song YT, Fukumori I, Shum CK, Yi Y (2012) Merging tsunamis of the 2011 Tohoku-Oki earthquake detected over the open ocean. Geophys Res Lett. https://doi.org/10.1029/2011GL050767

Tapley BD, Bettadpur S, Ries JC, Thompson PF, Watkins MM (2004) GRACE measurements of mass variability in the Earth system. Science 305(5683):503-505. https://doi.org/10.1126/scien ce. 1099192

Tapley BD, Watkins MM, Flechtner F, Reigber C, Bettadpur S, Rodell $\mathrm{M}$ et al (2019) Contributions of GRACE to understanding climate change. Nat Clim Change 9:358-369. https://doi.org/10.1038/ s41558-019-0456-2

Tsai VC, Ampuero JP, Kanamori H, Stevenson DJ (2013) Estimating the effect of Earth elasticity and variable water density on tsunami speeds. Geophys Res Lett 40(3):492-496. https://doi.org/10.1002/ grl.50147

Watada S (2013) Tsunami speed variations in density-stratified compressible global oceans. Geophys Res Lett 40(15):4001-4006. https://doi.org/10.1002/grl.50785

Weigelt M (2017) The acceleration approach. In: Naeimi M, Flury J (eds) Global gravity field modeling from satellite-to-satellite tracking data. Lecture notes in earth system sciences. Springer, Berlin, pp 127-160. https://doi.org/10.1007/978-3-319-49941-3_4

Yoshimoto M, Watada S, Fujii Y, Satake K (2016) Source estimate and tsunami forecast from far-field deep-ocean tsunami waveformsthe 27 February $2010 M_{w} 8.8$ Maule earthquake. Geophys Res Lett 43(2):659-665. https://doi.org/10.1002/2015GL067181

Yu Y, Chao BF, García-García D, Luo Z (2018) Variations of the Argentine Gyre observed in the GRACE time-variable gravity and ocean altimetry measurements. J Geophys Res Oceans 123:5375-5387. https://doi.org/10.1029/2018JC014189 